\title{
MEMPERKENALKAN MANAJEMEN KEUANGAN DENGAN SKALA PRIORITAS KEUANGAN PADA IBU-IBU RUMAH TANGGA KELURAHAN PONDOK BENDA
}

\author{
${ }^{1}$ Neneng Khoiriah, ${ }^{2}$ Dewi Ningsih, ${ }^{3}$ Sari Karmiyati, ${ }^{4}$ Aan Purnama, \\ ${ }^{5}$ Abdullah \\ Dosen Fakultas Ekonomi Universitas Pamulang \\ Email : ${ }^{1}$ nng_nng@ymail.com
}

\begin{abstract}
ABSTRAK
Kegiatan pengabdian kepada masyarakat yang dilakukan oleh tim dosen program studi Manajemen S1 Universitas Pamulang (Unpam) tahun 2019, merupakan kegiatan pengabdian kepada masyarakat yang menitikberatkan pada pengelolaan keuangan rumah tangga dengan skala prioritas bagi ibu - ibu rumah tangga sebagai pengelola keuangan keluarga. Kegiatan ini dibagi menjadi 2 tahap, yaitu tahap pertama berupa pemaparan mengenai manajemen keuangan dengan sekala prioritas keuangan rumah tangga dan tahap kedua berupa pelatihan pencatatan keuangan rumah tangga dengan hasil pencatatan yang dilakukan oleh ibu - ibu tersebut, diperoleh hasil bahwa sebanyak 69\% ibu - ibu rumah tangga tersebut dapat mengatur pengelolaan rumah tangga dengan baik karena dari hasil penghitungan diperoleh hasil yang surplus yang artinya pada akhir bulan ada dana sisa yang dapat disimpan (ditabung) / dipergunakan untuk hal yang lain, sedangkan sebanyak $31 \% \mathrm{ibu}$ - ibu rumah tangga belum dapat mengatur pengelolaan keuangan rumah tangga dengan baik. Dengan adanya kegiatan ini diharapkan ibu - ibu kelurahan pondok benda dapat memahami cara mengelola keuangan rumah tangga beserta memahami bagaimana cara mencatat keuangan dengan skala prioritas keuangan keluarga
\end{abstract}

\section{Kata Kunci: Pengelolaan Keuangan, Skala Prioritas, Ibu Rumah Tangga, Kelurahan Pondok Benda}

\section{PENDAHULUAN}

Masalah utama sebuah keluarga memang banyak bersumber dari masalah seputar keuangan, bahkan bisa menjadi perselisihan dalam keluarga. Meskipun masalah keluarga bukan hanya berarti kekurangan uang, karena terkadang keluarga yang berlebihan uang pun memiliki masalah, atau juga ada keluarga yang bingung bagaimana mengatur uang yang penghasilannya pas-pasan, sementara gaya hidup yang modern menuntut eksistensi keluarga ditengah masyarakat. Sering terjadi dalam keluarga pengeluaran-pengeluaran yang tidak berguna hanya untuk memenuhi eksistensinya di masyarakat. Masalah diatas sering menjadi penyebab pertengkaran keluarga dan tak jarang berujung pada perpisahan. Padahal dambaan setiap pasangan adalah memiliki keluarga sejahtera. Namun ditengah perjalanan 
rumah tangga, kebutuhan semakin meningkat apalagi ditambah dengan adanya anak yang hadir.

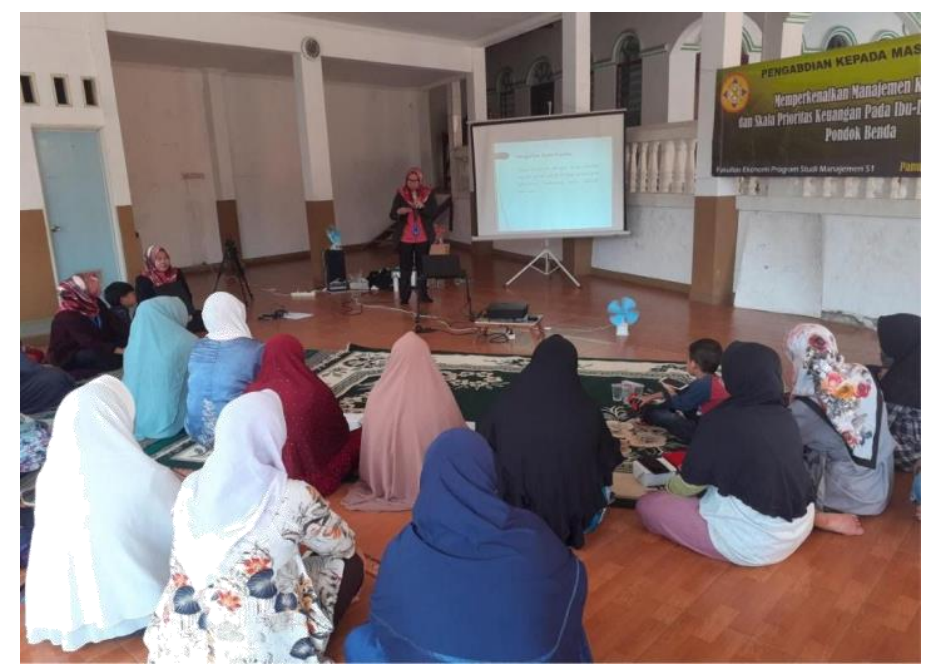

Gambar 1. Suasana Pemaparan Materi Pengelolaan Keuangan Skala Prioritas

Belakang ini harga kebutuhan pokok semakin meningkat, sementara pendapatan dari rumah tangga terbilang rendah atau terbatas, ditambah lagi dengan gaya hidup masyarakat mengikuti tren perkembangan sosialita maka pengeluaran menjadi tidak terkontrol hanya untuk sekedar membeli barang-barang yang kurang berguna bagi kebutuhan keluarga yang sebenarnya. Kondisi ini dialami oleh para ibu-ibu rumah tangga, khususnya ibu-ibu rumah tangga kelurahan Pondok Benda terutama mereka yang berpendapatan menengah ke bawah.

keuangan keluarga. Apabila dibiarkan terjadi terus menerus hal ini bisa menjadi masalah serius yang berkembang di masyarakat luas. Terkadang keluarga yang berlebihan uangpun memiliki masalah, atau juga ada keluarga yang bingung bagaimana mengatur uang yang penghasilannya pas-pasan, sementara gaya hidup yang modern menuntut eksistensi keluarga di tengah masyarakat.

Dari wawancara yang dilakukan, diperoleh kenyataan bahwa tidak satu pun kepala keluarga pernah melakukan pengelolaan kauangan keluarga yang jelas. Mereka hanya membelanjakan pendapatannya tanpa memiliki perencanaan yang baik, sehingga pada saat tertentu dimana harus mengeluarkan dana secara medadak banyak keluarga yang kebingungan, sehingga mencari jalan pintas dengan berhutang.

Dengan memberikan kesadaran, pengetahuan dan ketrampilan bagaimana mengatur keuangan keluarga dengan baik, melalui metode sederhana untuk menabung dan membuat anggaran, diharapkan akan membantu keluarga dalam megelola keuangan dan masa depan yang baik. 


\section{METODE PELAKSANAAN KEGIATAN}

Pelaksanaan kegiatan pengabdian pada masyarakat ini dikemas dengan menggunakan pendekatan pembelajaran latihan dan implementasi. Kegiatan dilakukan menggunakan metode ceramah, diskusi dan latihan. Agar tujuan pengabdian dapat tercapai maka dilakukan langkah-langkah dalam pelaksanaan kegiatan pengabdian ini sebagai berikut;

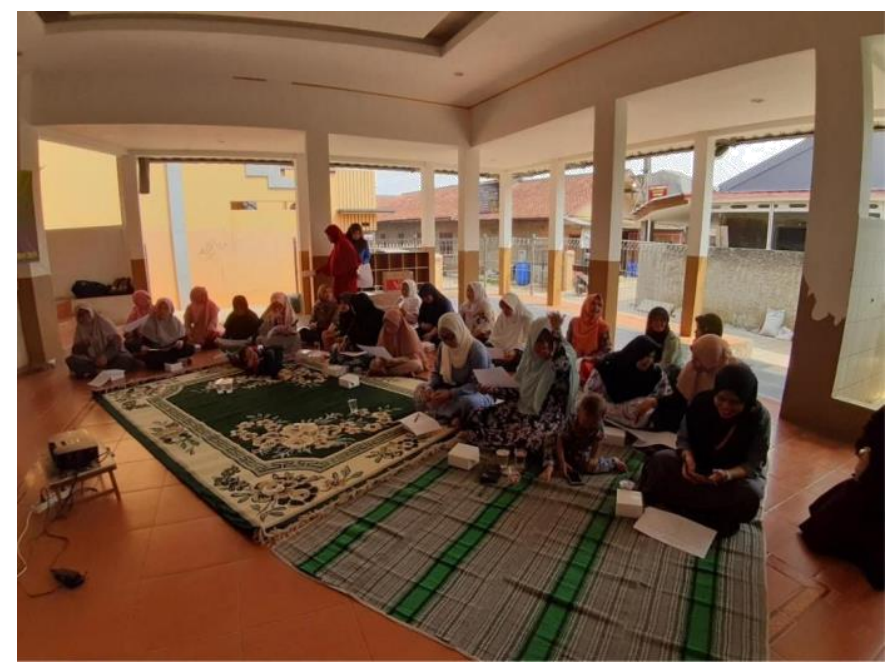

Gambar 2. Suasana Peserta Dalam Praktek Pencatatan Keuangan Rumah Tangga.

Pemberian materi. Metode yang digunakan untuk memberikan pengetahuan dan pemahaman mengenai pengelolaan keuangan melalui metode ceramah. Materi yang disampaikan dalam ceramah ini dimulai dengan memperkenalkan tentang manajemen keuangan, kebutuhan dan skala prioritas, hal ini untuk membuka wawasan mengenai skala prioritas dalam mengelola keuangan. Peserta diberikan gambaran umum mengenai pengelolaan keuangan menggunakan skala prioritas.

Diskusi. Peserta pelatihan diberi kesempatan untuk mendiskusikan permasalahan yang berkaitan dengan keuangan dan cara menysunnya menggunakan skala prioritas.

Quesioner. Sebelum pelaksanaan pemberian materi, peserta diberikan quesioner sebagai pre test untuk melihat sejauh mana peserta memiliki pengetahuan terkait materi sebelum ceramah untuk mendapatkan pengetahuan pengelolaan keuangan.

\section{HASIL DAN PEMBAHASAN}

Kegiatan pengabdian masyarakat tahun 2019/2020 ini telah mencapai kemajuan hasil pelaksanaan sebesar 100\%. Mereka melakukan pelatihan-pelatihan membuat anggaran pendapatan dan pengeluaran yang diberikan serta keaktifan peserta dalam diskusi yang diberikan untuk membahas soal-soal latihan yang diberikan. Secara rinci hasil pengabdian masyarakat dalam bentuk pengelolaan keuangan dengan menggunakan skala prioritas keuangan tersebut adalah dengan 
memberikan pemahaman dasar-dasar pembuatan anggaran pernadapatan dan pengeluaran, membuat skala prioritas dan melakukan latihan-latihan.

Pada tahapan ini juga dilakukan pembahasan mengenai penyusunan anggaran pendapatan dan pengeluaran, serta mempraktikannya dalam kehidupan sehari-hari sehingga menjadi suatu kebiasaan. Oleh karena itu pembahasan akan terus dilakukan sampai peserta mengerti dan memahami yang disampaikan.

Hasil analisis menunjukan bahwa umumnya peserta belum memahami bagaimana pengelolaan ekonomi dan keuangan keluarga yang baik. Selama ini yang dilakukan oleh mereka adalah melakukan pengeluaran untuk kebutuhan rumah tangga tanpa perhitungan dan tidak tersisa, semua dihabiskan pada periode tersebut. Padahal pada kenyataannya mereka sering mengalami kebutuhan secara mendadak, seperti anggota keluarga sakit dan ada saudara datang bertamu. Kondisi ini jika dihitung secara matematis nampak menimbulkan biaya yang tidak sedikit sehingga belum waktu habis bulan gaji sudah habis. Banyak hal yang harus dibenahi mulai dari pengendalian konsumsi dan pengeluaran-pengeluaran yang tidak perlu seperti terlalu banyak mengkonsumsi rokok yang bagi para suami mereka kebutuhan pokok yang tidak bisa ditawar.

Mereka umumnya tidak pernah melakukan pembukuan keuangan keluarga, pengelolaan keuangan cenderung mengalir apa adanya dan kurang menyadari manfaat dari pembukuan keuangan. Padahal pembukuan keuangan penting untuk dilakukan meski dalam bentuk yang sederhana sekalipun. Dengan adanya pembukuan maka pengeluaran lebih terarah dan terkontrol. Dengan cara ini diharapkan agar terhindar dari pemborosan yang bisa berakibat terjerat hutang, bahkan konflik keluarga yang seharusnya tidak perlu terjadi. Sebaliknya, diharapkan akan ada efisiensi sehingga dapat menabung dan berinvestasi sehingga keluarga tetap sejahtera untuk jangka waktu panjang

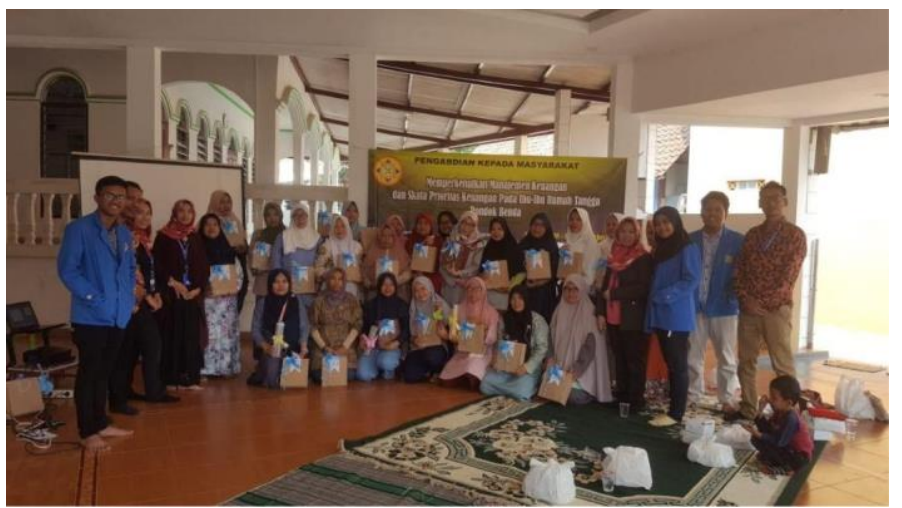

Gambar 3. Suasana antusias peserta ibi-ibu kelurahan Pondok Benda

\section{KESIMPULAN DAN SARAN}

Manajemen keuangan keluarga merupakan keterampilan yang harus dimiliki oleh seorang ibu sebagai pemegang keuangan keluarga. Melalui manajemen yang baik dan cermat maka pendapatan yang diperoleh keluarga 
diharapkan dapat digunakan tepat guna, tepat waktu, tepat tempat, tepat harga, dan tepat kualitas. Harapannya melalui penyuluhan ini, kita dapat mengambil hikmah bahwa berapapun rejeki yang diberikan Tuhan kalau kita syukuri dan gunakan secara benar dan tepat, ternyata akan membawa nikmat dalam menjalani kehidupan.

Kegiatan memperkenalkan manajemen keuangan dengan skala prioritas kepada ibu-ibu rumah tangga yang berbentuk pemahaman dan latihan menyusun anggaran pendapatan dan pengeluaran. Hampir semua peserta antusias dan merasakan manfaat Pelatihan. Pelaksanaan pengabdian untuk peserta ibu-ibu rumah tangga keluarahan Pondok Benda ini dapat disimpulkan berhasil sampai tahap implementasi praktik kehidupan sehari-hari. Keberhasilan ini ditunjukan antara lain; (1) Adanya respon positif dari peserta mengingat kegiatan pengabdian merupakan kebutuhan peserta dalam rangka peningkatan kualitas perencanaan keuangannya. (2) Sebagian besar peserta memahami anggaran pendapatan pengeluaran, menyusun skala prioritas kebutuhan, serta mampu mengambangkan kemampuan mengelola keuangan keluarga dengan baik

\section{DAFTAR PUSTAKA}

A Sobarna, S Hambali, S Sutiswo, D Sunarsi. (2020). The influence learning used $\mathrm{ABC}$ run exercise on the sprint capabilities. Jurnal Konseling dan Pendidikan 8 (2), 67-71

A Sobarna. (2015). The Mindset Of Physical Exercise (Pe) Teachers In District 134 Unpas On Their Understanding Of Physical Education After Completing InService Teacher Education And Professional. Journal Of Indonesian Physical Education And Sport 1 (2)

A Sudarsono, D Sunarsi. (2020). Pengaruh Kualitas Pelayanan Dan Varian Produk Terhadap Keputusan Pembelian Pada Laboratorium Klinik Kimia FarmaBintaro. Value: Jurnal Manajemen dan Akuntansi 15 (1), 16-26

Agus Sartono (2014). Manajemen Keuangan Teori dan Aplikasi. Yogyakarta : BPFE AgusSartono, 2001, Manajemen Keuangan Teori dan Aplikasi,BPFE, Yogyakarta

Artur J. Keown, John D. Martin, J. William Petty, David F. Scott, JR, 2011, Manajemen Keuangan,Indeks, Jakarta.

Brigham, Eugene F, dan Houston, Joel F, 2011. Dasar-Dasar Manajemen Keuangan Essential of FinancialManagement. edisi 11. Penerbit Salemba Empat, Jakarta.

D Prasada, S Sarwani, M Catio. (2019). Pengaruh Kompensasi Dan Lingkungan Kerja Terhadap Kinerja Karyawan Pada PT. Mitra Adiperkasa, Tbk. Jurnal Manajemen, Bisnis dan Organisasi (JUMBO) 3 (3), 195-207

D Sunarsi. (2014). Pengaruh Gaya Kepemimpinan, Motivasi dan Disiplin Kerja Terhadap Kinerja Pendidik. Universitas Pamulang

Darsono dan Ashari. 2005. Pedoman Praktis Memahami Laporan Keuangan. Jakarta: Salemba Empat.

Gumilar, I., Sunarsi, D. (2020). Comparison of financial performance in banking with high car and low car (Study of banks approved in the kompas 100 index 
for the period 2013-2017). International Journal of Psychosocial Rehabilitation. Volume 24 - Issue 7

Irham, Fahmi. 2012. Pengantar Manajemen Keuangan. Bandung: Alfabeta.

Kasmir. 2011. Pengantar Manajemen Keuangan.Jakarta: Kencana

Kasmir. 2015. Analisis Laporan Keuangan.Penerbit PT. RajaGrafindo Persada, Jakarta Martono, dan Agus. 2008. Manajemen Keuangan, Yogyakarta:EKONISIA. Siswanto. 2016. Pengantar Manajemen. Bandung. Bumi Aksara.

L Nofiana, D Sunarsi. (2020). The Influence of Inventory Round Ratio and Activities Round Ratio of Profitability (ROI). JASa (Jurnal Akuntansi, Audit dan Sistem Informasi Akuntansi) 4 (1), 95-103

Maddinsyah, A., Sunarsi, D., Hermawati, R., Pranoto. (2020). Analysis of location selection effect on the user decision that influcence the success of the service business of micro, small and medium enterprise (MSME) in bandung timur region. International Journal of Advanced Science and Technology. Vol. 29 No. 06

Purwanti, P., Sarwani, S., \& Sunarsi, D. (2020). Pengaruh Inovasi Produk Dan Brand Awareness Terhadap Keputusan Pembelian Konsumen Pada Pt. Unilever Indonesia. Inovasi, 7(1), 24-31.

RW Amelia, D Sunarsi. (2020). Pengaruh Return On Asset Dan Return On Equity Terhadap Debt To Equity Ratio Pada Pt. Kalbe Farma, Tbk. Ad Deenar: Jurnal Ekonomi dan Bisnis Islam 4 (01), 105-114D Sunarsi. (2014). Pengaruh Gaya Kepemimpinan, Motivasi dan Disiplin Kerja Terhadap Kinerja Pendidik. Universitas Pamulang

Sobarna, A. (2017). Gaya Mengajar, Keterampilan Motorik Dan Hasil Belajar Lari Cepat. JSKK (Jurnal Sains Keolahragaan dan Kesehatan), 2(2), 46-49.

Sunarsi, D., \& Asmalah, L. (2018). Pelatihan Manajemen Pengembangan Diri Bagi Penerima Beasiswa RZIS UGM Dan Dompet Shalahuddin Jogjakarta. Jurnal Pengabdian Dharma Laksana, 1(1), 51-60.

Sunarsi, D., \& Erlangga, A. (2020). The Effect of Leadership Style and Work Environment on the Performance of Stationary Pump Operators in the Water Resources Office of West Jakarta City Administration. International Journal of Advances in Social and Economics, 2(3).

Sunarsi, D., Kustini, E., Lutfi, A. M., Fauzi, R. D., \& Noryani, N. (2019).

Penyuluhan Wirausaha Home Industry Untuk Meningkatkan Ekonomi Keluarga Dengan Daur Ulang Barang Bekas. BAKTIMAS: Jurnal Pengabdian pada Masyarakat, 1(4), 188-193.

Sunarsi, D., Kusjono, G., \& Nuryana, I. (2019). Pelatihan Manajemen Penguasaan

Kelas Dan Pembuatan Bahan Ajar Bagi Tenaga Pengajar Sukarela Taman Belajar Kreatif Mekarsari. Jurnal Pengabdian Dharma Laksana, 2(1), 41-44. 